\title{
La teoría pura del derecho y la exclusión de la sociología*
}

\author{
José Fredy Aristizábal"
}

Recibido: 6 de junio de 2018 - Aprobado: 15 de agosto de 2018

\section{Resumen}

Hans Kelsen considera en su obra Teoría pura del derecho, que la ciencia jurídica debe separarse de otras ciencias. La razón de Kelsen consiste en su consideración de que la sociología ha sido atrapada por el empirismo racionalista y su motivación es que el derecho no puede ser reducido a una ciencia auxiliar de la sociología, lo que lo lleva a construir un estatuto propio de la ciencia jurídica con un corte racionalista. Ahora bien, el presente artículo tiene por finalidad analizar argumentos utilizados por Hans Kelsen, uno de los mayores referentes del derecho contemporáneo, para excluir la sociología de su construcción teórica "la teoría pura del derecho". Así pues, la posición del positivismo racionalista de manera alguna representa el pensamiento general de la sociología, por tanto es un error desconocer el papel fundamental de la sociología en la construcción de los sistemas normativos jurídicos. La metodología empleada es de naturaleza holística, es decir, obedece a una simbiosis entre análisis y reflexión para tratar de comprender una de las razones planteadas en la teoría pura del derecho, que desconoce el papel de la sociología en la modelación de las normas jurídicas.

\footnotetext{
*Artículo producto del proyecto de investigación titulado: "Reformas constitucionales al umbral electoral en el contexto del posconflicto en Colombia”, gestionado en la Fundación Universitaria Autónoma de las Américas (UAM), sede Pereira. Citar como: Aristizábal, J. F. (2019). La teoría pura del derecho y la exclusión de la sicología. Revista IUSTA, 1(50), 121-143. DOI: https://doi. org/10.15332/1900-0448.2019.0050.05

** Abogado de la Universidad Libre, especialista en Derecho Laboral y Seguridad Social, magíster en Derecho de la Universidad de Manizales. Docente investigador de la Fundación Universitaria Autónoma de las Américas (UAM), sede Pereira. Correos electrónicos: jose.aristizabal@uam.edu.co jfadelascasas@gmail.com - Orcid: https://orcid.org/0000-0002-1632-5243.
} 
Palabras clave: sociología, ciencias naturales, ciencias sociales, empirismo, racionalismo, positivismo.

\title{
The pure theory of LAW AND The EXclusion of Sociology
}

\begin{abstract}
Hans Kelsen considers in his work "Pure theory of law" that legal science must be separated from other sciences. Kelsen's reason consists in his consideration that sociology has been trapped by rationalist empiricism, and his motivation is that Law can not be reduced to an auxiliary science of sociology, which leads him to construct a statute of his own legal science, with a rationalist cut. However, the article is a partial result of research, which analyzes the arguments used by Hans Kelsen, one of the major references of contemporary law, to exclude sociology from its theoretical construction "The Pure Theory of Law". Thus, the position of rationalist positivism in no way represents the general thinking of sociology, therefore it is a mistake to ignore the fundamental role of sociology in the construction of legal normative systems. The methodology used is of a holistic nature, that is, it obeys a symbiosis between analysis and reflection to try to understand one of the reasons stated in the pure theory of law that ignores the role of sociology in the modeling of legal norms.
\end{abstract}

Keywords: Sociology, natural sciences, social sciences, empiricism, rationalism, positivism.

\section{A teoria PURA do DiREITo E A EXCLUSÃo DA SOCIOLOGIA}

\section{Resumo}

Hans Kelsen considera em sua obra "Teoria pura do direito" que a ciência jurídica deve ser separada de outras ciências. A razão para Kelsen é sua consideração que a sociologia foi preso pelo empirismo racionalista, e sua motivação é que a lei não pode ser reduzida a uma ciência auxiliar da sociologia, que o leva a construir um estatuto adequado ciência jurídica, com um corte racionalista. Agora, o artigo pretende analisar argumentos utilizados por Hans Kelsen, uma das principais referências do direito contemporâneo, para excluir a sociologia de sua construção teórica a teoria pura do direito. Assim, a posição do positivismo racionalista não 
representa de modo algum o pensamento geral da sociologia, portanto é um erro ignorar o papel fundamental da sociologia na construção de sistemas normativos legais. A metodologia é de natureza holística, ou seja, devido a uma simbiose entre a análise e reflexão para tentar entender uma das razões decorrentes da "teoria pura do direito" que ignora o papel de sociologia na formação de normas legais.

Palavras-chave: sociologia, ciências naturais, ciências sociais, empirismo, racionalismo, positivismo.

\title{
Introducción
}

\section{La teoría pura del derecho y la exclusión de la sociología}

\author{
"La razón se escondía en un pozo junto con la verdad, su bija. \\ Nadie sabia dónde estaba ese pozo, de haberlo sabido, \\ (algunos pocos entendidos) habrían descendido a él para degollar \\ a esa bija y a la misma madre". \\ (Voltaire, I985, p. 512).
}

La teoría jurídica es mucho más que idear recursos discursivos. La teoría jurídica es, tal vez, la tarea jurídica más exigente y compleja (Castro, 2018); y en este sentido, resulta procedente hacer referencia a la obra de Kelsen. De la primera lectura de la Teoría pura del derecho (Kelsen, 2000), pueden surgir muchas dudas pero una en especial se ha convertido en el objeto de esta investigación, el cual es la apreciación del autor sobre la sociología.

Kelsen (2000) considera que el derecho, visto como una ciencia jurídica, debe mantenerse al margen de otras ciencias como la política, la psicología y la sociología.

Hace casi un cuarto de siglo que emprendí la tarea de elaborar una teoría pura del derecho, es decir, una teoría depurada de toda ideología política y de todo elemento de las ciencias de la naturaleza, y consciente de tener un objeto regido por leyes que le son propias. Mi finalidad ha sido desde el primer momento elevar la teoría del derecho, que aparecía expuesta esencialmente en trabajos más o menos encubiertos de política jurídica, al rango de una verdadera ciencia que ocupara un lugar al lado de las otras ciencias morales (p. 9). 
De ahí proviene el título de su obra Teoría pura del derecho: "Al calificarse como teoría 'pura' indica que entiende constituir una ciencia que tenga por único objeto al derecho e ignore todo lo que no responda estrictamente a su definición” (p. 15).

De esta manera la sociología, por ser una ciencia nueva, era objeto de múltiples discusiones que se circunscribían a su validez, a su cientificidad, a su pertinencia y a su relación con otras ciencias, lo que muy seguramente observó Kelsen sobre lo cual tomó la decisión de excluirla de su teoría. Pero no se puede hablar de una decisión tomada en forma particular para cada una de las disciplinas mencionadas en su obra, pues las disciplinas que menciona y excluye Kelsen formaban un corpus coherente respecto de los sucesos de la época. Se trataba de una época convulsa, ad portas de la Primera Guerra Mundial, cuando los nuevos sociólogos no se podían abstraer de los temas políticos, de los temas del Estado y de la estructura que este debía tener. Además, excluyó otras ciencias como la psicología que había sido drásticamente transformada por Sigmund Freud, con quien Kelsen trabó amistad (Higuera, 2018).

En esta forma, las razones que llevaron a Kelsen a construir una teoría del derecho que excluyera otras disciplinas, que para otros autores son cruciales en la reflexión sociojurídica, radican en su consideración de que más que una teoría se trata de un método científico del derecho. Sin embargo, en el documento no hay rastros de ello. Se trata, quizá, de una ubicación relativa a las concepciones modernas concernientes a:

1. El empirismo vs. el racionalismo. Como se sabe, la perspectiva racionalista de Descartes fue contradicha por la perspectiva empirista de Locke y Bacon.

2. El iluminismo racionalista vs. el Romanticismo. E1 Romanticismo de finales del siglo XVIII, que incorpora en el pensamiento elementos diferentes a la razón, se opuso al racionalismo de la Ilustración (Adorno y Horkheimer, 2007).

3. El derecho como ciencia vs. el derecho como doctrina de principios.

4. La historia del derecho vs. el derecho en la historia.

En concordancia con lo dispuesto en líneas anteriores, es importante resaltar los cambios en las normas jurídicas y la importancia que se le da al proceso judicial para efectos de la eficacia, celeridad, protección y conservación de las garantías al debido proceso (Herrera, 2017), y a la vez, no olvidar que uno de los desafíos a los que se 
enfrenta el Estado de derecho es el que se deriva de la pérdida de soberanía de los mismos, por el desplazamiento de las fuentes del derecho fuera de sus confines y el debilitamiento del papel garantista de las Constituciones nacionales (Blanco, 2011).

\section{Los principios básicos de la modernidad}

Conviene partir de la discusión sobre el significado del conocimiento en relación con la certeza perseguida por el racionalismo continental (Descartes, Spinoza, Leibnitz) y el pensamiento posible, buscado por el empirismo inglés (Locke, Bacon, Hume, Berkeley).

La angustia cartesiana, como la llama Richard Bernstein (1985), consistió en encontrar una verdad de la cual no se pudiera dudar. Esta necesidad de certeza se elaboró respecto a la dicotomía entre sujeto (res cogitans) y objeto (res extensa), es decir, entre un interior que conoce algo exterior. Y ese vínculo entre estas dos substancias (conocimiento y mundo) no pudo ser resuelto porque el único puente entre uno y otro, los sentidos, no ofrecía, para Descartes, ninguna confianza. Entonces, la única posibilidad de contar con una verdad confiable, con una verdad de la cual no pudiera dudarse, una verdad absoluta la proporcionaba la propia razón, es decir, el mundo subjetivo que no exigía la mediación sensorial (Abbagnano, 1981/1996).

El empirismo, en la orilla opuesta, le daba a la experiencia la responsabilidad del conocimiento; en su forma moderna surge en el espíritu práctico inglés, que prefiere el conocimiento posible sobre el conocimiento absoluto. Son conscientes de que los sentidos tienen limitaciones, pero saben también que son las únicas ventanas al mundo y definen que el conocimiento proviene en su totalidad de la experiencia sensorial. Los autores principales de esta tendencia son George Berkeley, Francis Bacon, John Locke y David Hume. Berkeley encuentra, por ejemplo, que un objeto no se puede conocer, pues el objeto del conocimiento son solo las sensaciones que se tengan de él. Esto lo extiende incluso a las propiedades matemáticas. De manera semejante, Hume sostiene que la causalidad no se puede conocer ni se puede demostrar. La causalidad es solo una esperanza de que si una cosa sucede, va a suceder otra que suele estar correlacionada con la primera, pero solo la imaginación liga la primera con la segunda en forma de causalidad. De aquí se derivan algunos principios de las investigaciones actuales en las que se usa la estadística, en las cuales no se habla nunca de causalidad sino de correlaciones, de probabilidades, según el número de veces en que se presenta un evento. Es decir, 
son investigaciones que renuncian de antemano a una explicación causal y se limitan a describir frecuencias de aparición de los fenómenos que se presentan en una observación (Padrón, 2007). Todo lo anterior sin olvidar que la responsabilidad civil está subordinada a la existencia de los elementos que la condicionan, siendo estos: la culpa, el daño y la relación de causalidad entre la conducta culposa y el daño (Torres y Ramírez, 2018).

\section{El nacimiento de las disciplinas}

La racionalidad de la modernidad impulsó, además, la especialización del conocimiento y con ella, el nacimiento de las disciplinas. Como se sabe, en la antigüedad clásica y hasta la Alta Edad Media, las artes liberales provenían del trivium y del cuadrivium, que constituían los saberes nobles que eran la astronomía, la gramática, la retórica, la geometría, la dialéctica, la aritmética y la música (Da Costa, 2006) (nótese que todos tenían nombres y símbolos femeninos). Estos saberes se distinguían de los oficios viles, de los esclavos y luego de los siervos, considerados como oficios mecánicos. Luego, en el siglo XV, Enrique de Villena llega a enumerar unas cien artes, puesto que los maestros artesanos fueron reconocidos como personas de gran conocimiento (Villalba, 2016). Pero en la Modernidad, especialmente por influjo de las observaciones impulsadas por el empirismo, se especializaron y se multiplicaron los saberes. Newton le dio un impulso formidable a la física y a la matemática, Descartes y Leibnitz a la matemática, y en las primeras universidades se impartieron saberes vinculados a la filosofía humanista del Renacimiento y a la teología. Entonces, fue surgiendo una división entre las "ciencias de la naturaleza" y las "ciencias del espíritu". En Alemania fueron las naturwissenschaften, cuyo propósito era nomotético, pues se trataba de explicar (erklären) los fenómenos externos mediante el acopio de información; y las geiseswissenschaften, o ciencias del espíritu, cuyo propósito era más bien entender, mediante la interpretación de la significación. Una división semejante surgió en Inglaterra donde se llamaron ciencias naturales y ciencias morales (Umbarila, 2018).

A las ciencias naturales pertenecen las matemáticas, la biología, la química, la física y la astronomía, y las ciencias sociales agruparon la economía, la política, la sociología, el derecho, la psicología, la filosofía, la teología y la ética, entre otras. De hecho, en muchas universidades norteamericanas, en la actualidad, la Facultad 
de Ciencias incluye solo las ciencias naturales, que son la física, la química y la biología, y todas las disciplinas sociales se agrupan en la "Facultad de Artes".

En el siglo XIX, August Comte funda la sociología con la pretensión de darle un estatuto científico al estudio de lo social, para lo cual, acude al método de la física propuesto por Newton y que gozaba de un prestigio enorme por ser considerado como el método científico por excelencia (Ángel y Herrera, 2011). Y en este mismo registro, Comte funda el positivismo como reacción frente al dogmatismo de la teología católica y contra el esoterismo de las explicaciones de lo humano.

Fue August Comte quien estableció para las ciencias, sin diferenciarlas entre naturales y sociales, el siguiente orden, de la más abstracta a la más concreta: matemáticas, astronomía, física, química, biología, psicología y sociología. Una ciencia de la sociedad es, pues, la "ciencia reina" en la jerarquía de Comte, puesto que sería la más compleja. A través de las ciencias sociales Comte creía que se podrían remediar todos los males sociales. Con esta esperanza, le trazó una intención a la sociología como una ciencia que podía tener una repercusión política. Esta discusión tiene su origen en el pensamiento del siglo XIX, pues Comte legó esta intención a Durkheim y a Weber, quienes se ocuparon de convertir al derecho en ciencia, puesto que hasta el momento era considerado un arte (artjuris).

\section{Entre la “dogmática jurídica” y la codificación}

La diatriba entre racionalismo y empirismo, que a partir de Kant se consideraba ya superada, continuó viva en el ámbito del derecho, pues el enfoque racionalista deriva en la construcción de sistemas jurídicos ideales cuyas bases radicaban en algunos principios, sometidos al método de la observación sin una mayor profundización en otros aspectos. Esta corriente, sin embargo, ignoraba algunas corrientes positivas. Es así como en Francia, durante el iluminismo, floreció una corriente de juristas que explicaban los problemas del derecho según el racionalismo. Se dice de estos juristas teóricos que en lugar de evaluar críticamente la ley positiva asumieron nuevas tareas como las de adoptar la ley positiva como dogma buscando con ello identificar las consecuencias y su interpretación.

Fue desarrollándose de este modo entre los juristas teóricos la presuposición de que su tarea no consistía más en evaluar críticamente la ley positiva sino en adoptarla 
como dogma con el fin de exponer sus consecuencias y la interpretación correcta de la misma (Nino, 1980, p. 15).

Por la misma época, se empiezan a concentrar las normas en un cuerpo al que denominaron código, surgiendo así lo que se conoció como la codificación. Se tenía la convicción de que los nuevos códigos eran completos, coherentes y precisos y conformaban sistemas autosuficientes para resolver la casuística. En esa forma, se consolida el nuevo derecho positivo.

Esto llevaba implícito una extrapolación al nuevo derecho positivo de las características formales que se atribuían anteriormente a los sistemas ideales que los juristas construían: se asumía que los nuevos códigos eran completos, coherentes y precisos, constituyendo sistemas autosuficientes para resolver cualquier caso concebible sin acudir a premisas que no se pudieran extraer de los materiales jurídicos positivos (Nino, 1980, p. 15).

La "dogmática jurídica” tiene su origen en la confrontación entre dos corrientes: el movimiento de codificación y el enfoque racionalista. Estas dos corrientes existían antes de la sanción de los nuevos códigos.

La tarea de esos juristas racionalistas, que estaban influidos por la filosofía del iluminismo, consistía principalmente en la construcción de sistemas jurídicos ideales estrictamente deducidos de unos pocos principios autoevidentes; esto se hacía desatendiendo casi totalmente las normas positivas vigentes en sus respectivos países antes de la codificación. Cuando los nuevos códigos fueron sancionados, ellos tuvieron un impacto profundo y radical en la teoría jurídica, puesto que los juristas debieron adoptar como objetivo preeminente el de dar cuenta del nuevo derecho positivo que se aproximaba considerablemente, tanto en relación a su contenido ideológico como respecto de sus propiedades formales de completitud, coherencia, precisión, etc., a los sistemas ideales por ellos propugnados (Nino, 1980, p. 14).

Los teóricos del derecho pretendieron exponer el derecho positivo con los mismos métodos deductivos y abstractos sin tener para ello en cuenta las consideraciones empíricas. 
Pero, al mismo tiempo, los teóricos del derecho pretendieron desarrollar su tarea de exponer el derecho positivo manteniendo la metodología propia del racionalismo, que había sido empleada en la construcción de sistemas ideales.

Siguieron concibiendo su labor como eminentemente deductiva y abstracta, y ajena a consideraciones empíricas. La escuela de "la jurisprudencia de conceptos" inspirada por Savigny y fundada, entre otros por Ihering en su primera etapa intelectual, proveyó las bases teóricas de esta pretensión de construir una ciencia puramente racional que tuviera, sin embargo, como único objeto al derecho vigente históricamente en cierto ámbito. El conceptualismo proclama a la legislación como única fuente de derecho, pero asume que la función de la teoría jurídica no consiste simplemente en describir el contenido de tal legislación, sino en descubrir las soluciones implícitas en la misma a través del análisis, clasificación y combinación de ciertos conceptos jurídicos fundamentales inherentes a todo sistema jurídico (Nino, 1980, p. 15).

Rudolf Ihering (2003) marca una fuerte influencia en el derecho alemán durante el siglo XIX, especialmente por su crítica al método jurídico reinante. Fue docente en la Universidad de Viena (1868), en la misma escuela en la que, años más tarde, estudiaría Hans Kelsen. Algunos de sus preceptos fueron seguidos más adelante por la sociología y en especial por la sociología jurídica, con la idea de juntar el derecho y la sociología, lo que va a ser criticado posteriormente por Kelsen (Weingarten, 2016).

\section{Heidelberg como epicentro de la sociología moderna}

La búsqueda de un método apropiado que explicara los problemas de la sociedad fue asumida por los sucesores de Comte, entre quienes se destacan Emile Durkheim y Max Weber entre otros. En esa época los autores se dieron a la tarea de darle el carácter de ciencia a las viejas artes siguiendo la orientación de Comte (Llano, 2017).

La ciencia, para ser considerada como tal, requiere un rigor conceptual. Las ciencias humanas adolecen, en principio, de falta de este rigor por lo que se hace necesario encontrar una medida que otorgue, a los conceptos utilizados por estas ciencias, un rigor suficiente; así nace en Weber la necesidad de elaborar tipos ideales, ya que elaborar conceptos de este tipo es fundamental para poder apropiarse de los 
fenómenos sociales que interesan a las ciencias de la cultura. Este nuevo instrumento conceptual representaba también la solución a un problema resultante de la metodología weberiana de la neutralidad valorativa, a saber, se trataba de mantener la exigencia estricta de la neutralidad axiológica de la ciencia, sin por ello aislar totalmente a los juicios de valor de origen primigenio. El método del tipo ideal permite distinguir de manera lógica entre los juicios valorativos y los juicios referidos a valores. El tipo ideal debería permitir la vinculación de los fenómenos sociales e históricos a valores últimos, sin que por ello se introdujesen juicios de valor en el proceso cognoscitivo (López, 2005).

Se le debe a Max Weber el haber diseñado un método con el cual, lo que hasta el momento se consideraba disciplina social, empezara a tratarse como ciencia (Lazarte, 2005). Weber explica que el "hecho social" (postulado por Durkheim y que era medible, cuantificable y observable a través de entrevistas, estadísticas, encuestas etc., es decir, de una clara posición racionalista) se debe diferenciar de la "acción social" (objetivo de toda ciencia social). La acción social es subjetiva, y en torno a ella gira lo que se percibe a través de los sentidos (deseos, motivos, fines, intenciones etc.).

En Heidelberg, además de Weber, confluyeron Georg Jellinek, Herman Kantorowicz, Eugene Ehrlich y otros pensadores en discusiones en torno al Estado, al derecho, a la política, a la economía y a la sociología, en un momento de convulsión social en toda Europa bajo el signo de la Revolución soviética.

Georg Jellinek (1851-1911), uno de los abogados del grupo de Heidelberg y cercano a Max Weber, fue tutor de Kelsen en su deseo de optar a la condición de docente. Jellinek, autor de Teoría del Estado, inspiró a Kelsen para que su trabajo de grado se orientara a una teoría del Estado. Entonces, Kelsen escribe La doctrina estatal de Dante Alighieri.

Ese círculo, además de la sociología, abordaba frecuentemente temas de psicología (animado por Sigmund Freud), economía, cultura y política. La situación política en Alemania, ad portas de la Primera Guerra Mundial, era candente, pues en palabras de Marx y Engels (1848/1998): “un fantasma recorre Europa”. En efecto, en Rusia la revolución era inminente en los albores de la Gran Guerra, de modo que las teorías de Marx sobre la sociedad, la economía, y la política eran el centro de las discusiones, no solo del círculo de Heidelberg sino de toda Europa. María Celia Duek (2009), refiriéndose a Weber y a otros sociólogos de la época, escribió: 
Los intereses políticos del joven nacido en Erfurt estaban forjados por los ideales político-nacionales (Alemania potencia), por un lado, y los ideales de responsabilidad social y justicia (aspiración al bienestar de campesinos y obreros), por otro. Se entendía que la preocupación por cuestiones sociales era el único modo de evitar los infortunios asociados al avance del industrialismo moderno (p. 252).

Entre los "socialistas de cátedra" se destacaban Lujo Brentano, Heinrich Herkner, Wilhelm Roscher, Gustav Schmoller y Adolf Wagner, quienes no aceptaban el ideal de la armonía social, propio del pensamiento económico liberal. Su propuesta ante los problemas de la Revolución Industrial, diferente a la de los socialistas y los socialdemócratas, era que la economía se orientara por ideales éticos y que el Estado regulara los contratos de trabajo. Se oponían al libre cambio y luchaban por mejorar la situación de la clase obrera, aunque reconocían las formas de propiedad y producción existentes (Duek, 2009).

Kelsen, entonces, preocupado por la arremetida revolucionaria contra el derecho, empieza a postular su posición de que la sociología y otras ciencias, incluyendo la política, debían separarse del derecho. Su intención no era descontextualizar la ciencia jurídica ni oponerse a la perspectiva revolucionaria, sino depurar el derecho respecto a intereses que desvirtuaran su estatuto científico.

Este grupo fundó en 1873 la "Asociación de Política Social”, con el propósito de elaborar propuestas de política social que pudieran ser tomadas en cuenta por el Estado. Se jactaba de haber superado los partidos y promovía una reforma social que representara un punto medio entre las consignas del laissez faire del liberalismo de Manchester y las del control absoluto del Estado del marxismo revolucionario. Weber ingresó a dicha asociación cuando esta abandonó la acción política y se dedicó exclusivamente a la actividad académica. Junto con Sombart, Tönnies y Alfred Weber, perteneció a la generación “joven” de la asociación, que se planteaba el problema de la actitud que debía adoptarse respecto a la obra de Marx y respondía de manera diferente a la de la generación vieja (Duek, 2009).

Sin embargo, es imposible cuestionar de cualquier forma la relación de los sociólogos con la política, ya que en la sociología se daban las mismas razones que llevan al debate entre sociología y derecho, pues es imposible deslindar la sociología de la política. Por supuesto, la política, la economía y la cultura son abordadas por la sociología, pero cada una de ellas vista como ciencia, se alternan el papel de ciencias auxiliares, reconociendo que esto no significa más que una necesaria 
transversalidad que ayuda a explicar sus postulados sin que por esa razón pierdan su carácter científico.

Fue quizás ese activismo político, además de la creencia de que el derecho era una ciencia auxiliar de la sociología, lo que llevó a Kelsen a separar la sociología del derecho. Sin embargo, es preciso analizar los sentimientos personales de Kelsen en relación con el círculo de Heidelberg que pudieron influir en él al escribir su Teoría pura del derecho.

Georg Jellinek, que tenía una relación muy cercana con Weber, accede a ser tutor de Kelsen que aspiraba a una plaza docente en la Universidad de Viena, de modo que Kelsen viaja a Heidelberg en 1906, ciudad que se había convertido en la sede académica de quienes querían darle cientificidad a las ciencias sociales. Por este vínculo, algunos autores, entre ellos Bobbio (1982), destacan de Kelsen el haberse formado en la escuela de Jellinek: “... el joven y ya reconocido jurista, formado en la Escuela de Jellinek...” (p. 58), pero esta afirmación puede no ser del todo exacta ya que el mismo Kelsen en su autobiografía (2008) deja entrever una cierta decepción con respecto a Jellinek:

Así, partí sin la bendición para mi futuro tan decisiva de mi profesor ordinario, hacia Heidelberg. Aquí dediqué un par de meses a trabajar intensivamente en mis "Hauptproblemen". No gasté tiempo en oír lecciones, solo visité el seminario de Jellinek, que no me ofreció un especial estímulo. Tampoco entré en una relación personal con el propio Jellinek. Él estaba rodeado por un círculo casi impenetrable de discípulos que lo admiraban y halagaban su vanidad de manera increíble (p. 84).

Este comentario de Kelsen indica un problema personal que pasó al plano académico, puesto que en la misma autobiografía, y refiriéndose a Jellinek, cuenta que:

Antes de ir a Heidelberg ya había estudiado sus obras con gran atención y me había formado la impresión de que en la esfera de la teoría jurídica era débil y poco original (p. 84).

Al parecer, durante su paso por Heidelberg, Kelsen ganó la primera batalla, puesto que la sociología fue considerada como ciencia gracias al método ideado por Max Weber. No obstante, el derecho, cuyo objeto de estudio también 
es la sociedad, no fue considerado como una ciencia autónoma, de modo que Kelsen emprende otra batalla para que el derecho fuera reconocido como ciencia autónoma.

\section{Kelsen y la autonomía de la ciencia jurídica}

Norberto Bobbio (1982) explica en una conferencia a la que fue invitado, su punto de vista sobre lo que el propio Kelsen consideró respecto al sentido de que su teoría encontraba su explicación de un modelo metodológico:

Después de haber dicho que la obra que está por publicar tiene un carácter prevalentemente metodológico, ya que entiende liberar la construcción de los conceptos jurídicos de elementos sociológicos y psicológicos (p. 21).

Uno de los temores de Kelsen era que la ciencia jurídica quedara subordinada a la política, temor que expresaba en el prefacio a la edición alemana cuando decía que el derecho no podía ser considerado como una ciencia auxiliar de otras ciencias como la sociología o la psicología: “... es el momento para que el derecho deje de ser el pariente pobre de las otras disciplinas científicas" (Kelsen, 2000).

Este temor lo reitera en la edición francesa cuando dice que uno de los fines de la teoría pura del derecho es mantener separada la ciencia jurídica de la política y de otras ciencias: "La teoría pura del derecho debe estar depurada de toda ideología política, de cualquier elemento de las ciencias de la naturaleza” (Kelsen, 2000).

La pretensión de Kelsen era elevar a ciencia lo que se veía como una "política jurídica”. Este autor consideraba que la ciencia del derecho debía estar al nivel de las ciencias morales (prefacio a la edición alemana). Con respecto a las ciencias naturales, afirmaba que estas se explican fundamentándose en el principio de causalidad:

Por naturaleza entendemos un orden o sistema de elementos relacionados los unos con los otros por un principio particular: el de causalidad. Toda ley natural hace aplicación a este principio (p. 16).

En relación con las ciencias sociales, a las cuales pertenece el derecho, Kelsen escribe: 
Por ser el derecho un fenómeno social, la ciencia del derecho forma parte del grupo de ciencias que estudian la sociedad desde distintos puntos de vista. Estas ciencias difieren en su esencia de las de la naturaleza, dado que la sociedad es una realidad totalmente distinta de la naturaleza (p. 16).

Como lo define Kelsen, la sociedad es el objeto de estudio de las ciencias sociales y, por tanto, de existir un principio que explicara por igual las dos ciencias, algo así como un principio estándar, serían entonces las ciencias naturales las que estudiarían la sociedad y no existirían por consiguiente métodos propios para estudiar la sociedad. En igual sentido, decía Kelsen que hay un principio que explica la conducta de los hombres, pero que este tampoco es igual al del principio de causalidad:

Pero si nos acercamos más percibiremos que en nuestros juicios sobre la conducta de los hombres aplicamos también otro principio, en todo diferente del principio de causalidad. La ciencia todavía no le ha dado un nombre universalmente admitido (p. 17).

Con esta diferenciación Kelsen aclara que las ciencias jurídicas no se pueden explicar como se explica la relación causa-efecto en el ejemplo de los metales: "Así, la ley según la cual un metal se dilata cuando se le aplica el calor establece una relación de causa a efecto entre el calor y la dilatación del metal" (p. 16). Kelsen establece la diferenciación del principio que mueve a las ciencias sociales de la siguiente manera:

Al igual que en la ley natural, la regla de derecho establece una relación entre dos hechos, pero mientras en la ley natural hay una relación de causa a efecto, la causalidad no interviene en la regla del derecho. El crimen no es la causa de la sanción; la sanción no es el efecto del acto ilícito. La relación que existe entre los dos hechos resulta de una norma que prescribe o autoriza una conducta determinada. Esta norma es el sentido que se da a uno o muchos actos que los hombres han cumplido en el espacio y en el tiempo y a los que se denomina costumbre, ley, fallo judicial, o acto administrativo (p. 18).

Nótese que en esta última cita no aparece referenciada la palabra jurisprudencia, puesto que la jurisprudencia es objeto de otro debate sostenido por Kelsen en relación con el iusnaturalismo. De todas formas, Kelsen da como razón para 
excluir a la sociología (también a la psicología y a la política) de su teoría pura del derecho, el que se pretenda explicar las ciencias sociales con el mismo principio de causalidad con el que se explican las ciencias naturales. Estas últimas son ciencias causales, junto con algunas ciencias sociales como la psicología, la sociología, la etnología y la historia, mientras que las ciencias normativas, como el derecho, obedecen a otro principio.

El principio de causalidad ha sido también aplicado a las conductas humanas consideradas como hechos pertenecientes al orden causal de la naturaleza; de aquí la constitución de ciencias causales como la psicología, la etnología, la historia o la sociología, que buscan explicar las conductas humanas estableciendo entre ellas relaciones de causa a efecto (p. 24).

Kelsen incluso llega a comparar estas ciencias con las ciencias naturales.

Si bien por su objeto pertenecen al grupo de ciencias sociales, son ciencias causales, de la misma especie que la física, la biología o la fisiología, de las cuales solo se diferencian por el grado menos elevado de precisión que han podido alcanzar hasta ahora (p. 24).

A las ciencias normativas como la ética y el derecho se les aplica el principio de imputación, pues, siendo igualmente ciencias sociales, no responden al principio de causalidad:

Que una ciencia sea calificada de normativa no significa que tenga por objeto prescribir una conducta determinada ni dictar normas aplicables a la conducta de los individuos. Su papel es solamente describir las normas y las relaciones sociales que ellas establece (p. 25).

Para Kelsen, en el principio causa-efecto no opera la voluntad humana, caso contrario al principio de imputación en el que es la voluntad humana la que determina el efecto. Para ser esa la única razón explicada por Kelsen, por lo menos explícitamente, conviene saber que los sociólogos, previos y contemporáneos a la aparición de la Teoría pura del derecho, pensaban igual, es decir, que los fenómenos sociales se explicaban según el principio de causalidad con el que se explican las ciencias naturales. 
Ya en su momento lo había manifestado Cristian Thomasius en su famosa frase "extra societatem non est jus in omni societate jus est..." es el documento en el que Kelsen hace esa afirmación: La teoría pura del derecho. Aparte de esa mención no hay más referencias. Si con la exclusión de la sociología lo que pretendía Kelsen era desvirtuar los planteamientos de causalidad de algunos sociólogos, lo que menos debió concebir fue hacer ver esto como una posición generalizada.

Conviene abordar otras consideraciones de Kelsen, no ya estrictamente sobre la sociología, pero que podrían tener alguna relación con el tema objeto de este análisis. Kelsen hace énfasis en que se confundían las "políticas jurídicas”, es decir, lo que debería ser, con lo que "es" el derecho. De todas formas, tanto racionalistas como empiristas buscaban llevar el derecho al rango de verdadera ciencia y no de ciencia auxiliar de otras como la sociología, pues el derecho, como toda ciencia, busca la objetividad y la exactitud (prefacio a la primera edición). Así, se establece que la estructura de la teoría de Kelsen se basa en los conceptos... el concepto de derecho, de sistema jurídico, de validez de la norma, etc. Y sobre esto, Kelsen diferencia la actividad realizada por los jueces y los abogados de la actividad ejercida en la ciencia del derecho.

Una razón de Kelsen es que el objeto de estudio de la ciencia pura del derecho no son las acciones humanas... como por ejemplo la actividad de los jueces (Nino, 1980, p. 23) y que la función de estos no es dar explicaciones causales. Lo entendía entonces como meros árbitros del proceso como en la época del Código Napoleónico. Es por esto que la ciencia del derecho debe ocuparse de los "hechos" y sus proposiciones deben hacer referencia a una realidad dada y no a un estado de cosas que no se dan en los hechos pero que se postulan como valiosos o deseables (p. 23).

Aunque Kelsen hace énfasis en que su teoría se basa en "lo que es", afirmó en relación con la jurisprudencia que es, en la práctica, una materialización del "deber ser", de modo que debía obedecer igualmente a un método científico. Dos sociólogos, de la época, Hermann Kantorowicz y Eugen Erlich, consideraban la jurisprudencia como una disciplina sociológica: "Respecto a Kantorowicz y a Erlich, Weber y Kelsen se encontraron en la misma parte de la barricada. Los dos sociólogos tendían a reducir la jurisprudencia a disciplina sociológica" (Bobbio, 1982, p. 61).

\footnotetext{
${ }^{1}$ Significa: "fuera de la sociedad no hay derecho; en toda sociedad hay derecho".
} 
Las diferencias con Kantorowicz y con Erlich no se limitaban a la mencionada anteriormente, el primero era representante y creador de lo que denominó el "derecho libre", en tanto que el segundo era defensor del "derecho viviente" (p. 62). Bobbio hace referencia a estas diferencias sostenidas por Kelsen respecto de las posiciones de estos sociólogos: "Además, ambos, el primero partidario belicoso del derecho libre, el otro cuestionador de la jurisprudencia formalista y estatalista en nombre del derecho viviente, también habían concebido sus escritos como armas de batalla política del derecho..." (p. 61).

\section{La codificación del derecho}

Fue la mezcla de empirismo-racionalismo-codificación e historicismo lo que pudo haber originado la "teoría pura del derecho" respecto a la exclusión de la sociología entre otras disciplinas. Kelsen en varias oportunidades escribe que "la teoría pura del derecho" es un método para explicar las ciencias jurídicas... es allí de donde radica su capacidad heurística. Los racionalistas tenían un método que se contraponía al positivismo, pese a lo cual paulatinamente fueron aceptando ideas del positivismo tratando de introducir una explicación racionalista (causa-efecto), pero Kelsen se opuso a este método para abordar el derecho porque este obedece a otra lógica que no es explicativa. El objeto Kelsen lo expresa en el prefacio de la primera edición que "era darle objetividad y exactitud al conocimiento del derecho". Esta posición era propia de "los países cuyas normas obedecen a la existencia de un ordenamiento jurídico por el cual se rigen, caso contrario de aquellos países, como Estados Unidos, que se guían más por las posiciones iusfilosóficas” (Kelsen, 2000). No obstante el afán de Kelsen de explicar su método científico, él lo hace en forma indirecta: "A pesar de esto, Kelsen no desarrolla explícita y sistemáticamente su modelo de ciencia jurídica, debiendo ser este reconstruido a partir de afirmaciones dispersas y a veces supuestos implícitos" (Nino, 1980).

Kelsen considera que los mandatos contenidos en las normas obedecen a unos hechos empíricos (experiencia) “... aunque en el caso de las normas positivas ellas tienen necesariamente cierta contrapartida constituida por hechos empíricos" (Nino, 1980, p. 23). Esto significa que el hombre hace las normas producto de la experiencia, nada muy distinto al sistema del common law que, a diferencia del civil law, toma decisiones sobre la marcha, pero son decisiones basadas en la experiencia de hechos acaecidos con anterioridad. La diferencia está en que las normas positivas 
ya están dadas de manera implícita en el ordenamiento jurídico, lo que cierra cualquier posibilidad a la subjetividad de quien esté llamado a tomar una decisión.

Kelsen considera improbable que un juicio de valor se pueda probar racionalmente... y considera que estos juicios no tienen un contenido cognoscitivo, es decir, demostrable racionalmente, y que en cada sociedad, en cada cultura, estos juicios de valor pueden ser diferentes. Los juicios de valor son manifestaciones emotivas o actitudes que no son uniformes para las personas, es decir, que algunos las asumen como parte de su forma de vivir, mientras que otros no las consideran (Nino, 1980, p. 77).

En estas razones, Kelsen sigue la ruta del derecho como ciencia (racionalismo vs. empirismo) (Gershenson, 2000), la norma (diferencia norma de ordenes o mandatos), validez (su pertenencia a un sistema jurídico... que no su existencia positiva, es decir no depende de si está escrita la norma o no, por ejemplo la costumbre), y juicios de valor (responden a las emociones y no son demostrables, es decir no les es aplicable un método racionalista).

Como contraposición a lo anterior, algunos autores del siglo XIX pretendieron darle a los juicios de valor un contenido cognoscitivo, pero para Kelsen las fórmulas para explicarlas son vacuas:

Estos autores sostienen, consecuentemente, que las definiciones que se han pretendido producir para captar el supuesto significado cognoscitivo de expresiones éticas como "justicia", constituyen formulas vacuas, y que esto es inevitable puesto que tales expresiones no tienen significado descriptivo que una definición pueda recoger (Nino, 1980, p. 77).

Hay dos situaciones que se dan en los momentos previos a la codificación: la primera es la existencia de normas positivas (Europa continental); la segunda es la presencia de juristas racionalistas que ignoraban esas normas positivas.

La tarea de esos juristas racionalistas, que estaban influidos por la filosofía del iluminismo, consistía principalmente en la construcción de sistemas jurídicos ideales estrictamente deducidos de unos pocos principios autoevidentes; esto se hacía desatendiendo casi totalmente las normas positivas vigentes en sus respectivos países antes de la codificación (Nino, 1980, p. 14). 
Según Nino, una vez se produce la codificación, aumenta el impacto sobre los racionalistas:

Cuando los nuevos códigos fueron sancionados, ellos tuvieron un impacto profundo y radical en la teoría jurídica, puesto que los juristas debieron adoptar como objetivo preeminente el dar cuenta del nuevo derecho positivo que se aproximaba considerablemente, tanto en relación a su contenido ideológico como respecto de sus propiedades formales de completitud, coherencia, precisión, etc., a los sistemas ideales por ellos propugnados (p. 14).

Pero la "adopción" hecha por los racionalistas con respecto al nuevo derecho positivo (codificado), no es otra cosa que la adecuación de una metodología racionalista a la compilación positivista (Russell, 1946/1961).

Fue desarrollándose de este modo entre los juristas teóricos la presuposición de que su tarea no consistía más en evaluar críticamente la ley positiva sino en adoptarla como dogma con el fin de exponer sus consecuencias y la interpretación correcta de la misma. Esto llevaba implícita una extrapolación al nuevo derecho positivo de las características formales que se atribuían anteriormente a los sistemas ideales que los juristas construían: se asumía que los nuevos códigos eran completos, coherentes y precisos, constituyendo sistemas autosuficientes para resolver cualquier caso concebible sin acudir a premisas que no se pudieran extraer de los materiales jurídicos positivos (Nino, 1980, p. 15).

Estos códigos en el derecho positivo fueron tomados por los teóricos del derecho según la metodología racionalista empleada para construir sistemas jurídicos ideales.

Siguieron concibiendo a su labor como eminentemente deductiva y abstracta, y ajena a consideraciones empíricas. La escuela de la "jurisprudencia de conceptos" inspirada por Savigny y fundada entre otros por Ihering en su primera etapa intelectual, proveyó las bases teóricas de esta pretensión de construir una ciencia puramente racional que tuviera, sin embargo, como único objeto al derecho vigente históricamente en cierto ámbito. El conceptualismo proclama a la legislación como única fuente de derecho, pero asume que la función de la teoría jurídica no consiste simplemente en describir el contenido de tal legislación, sino en descubrir las soluciones implícitas en la misma a través del análisis, clasificación y combinación 
de ciertos conceptos jurídicos fundamentales inherentes a todo sistema jurídico (Nino, 1980, p. 15).

Kelsen asimiló la generalización de la posición racionalista para excluir la sociología que había ajustado su pensamiento al positivismo sin renunciar a una explicación causal, según había observado inicialmente. Pero no se puede excluir toda una disciplina cuando se ha criticado una corriente de esa disciplina, que en sociología fue el positivismo racionalista que representaba al pensamiento de los sociólogos de la época. Y justamente ese es el problema de la crítica de Kelsen y, al mismo tiempo, su talón de Aquiles, en que asume literalmente la metonimia y desconoce el contexto social por asumir que la ciencia que lo estudia padece de los defectos de la razón que critica. Toma la parte por el todo y, según la metáfora que utiliza Marx, arroja el niño con el agua de la bañera.

\section{Conclusiones}

La teoría pura del derecho pretende que a la ciencia jurídica le sean ajenas la sociología y la psicología... y, más radical aún, excluye los hechos sociales y los hechos psicológicos junto con las ciencias que los abordan. La perspectiva racionalista de Kelsen quiere aislar el derecho de las circunstancias que lo originan, por la crítica al empirismo que le atribuía los fenómenos jurídicos solo a las condiciones históricas particulares, sin encontrar una racionalidad que pudiera impulsar el derecho hacia adelante y que pudiera originar diálogos interculturales en relación con las normas de cada sociedad.

No obstante, el separar el derecho de otras ciencias, entre ellas la sociología, pudo ser un esfuerzo para considerar el derecho como una ciencia autónoma, sin la condición vicaria respecto a otras ciencias. Hoy, cuando se pretenden superar las disciplinas para obtener una comprensión holística de una sociedad y se acude a las perspectivas multidisciplinares y, aún, transdisciplinares, el derecho tiene la capacidad para sentarse en las mesas de diálogo entre disciplinas porque tiene un estatuto propio y, al mismo tiempo, reconocer que su estatuto es insuficiente para explicar la sociedad pero su aporte es clave en los esfuerzos de comprensión de lo social. Como decía Christian Thomasius, "extra societatem non est jus in omni societate jua est"2 (Torres-Vásquez, 2001).

\footnotetext{
2 Significa: "fuera de la sociedad no hay derecho; en toda sociedad hay derecho".
} 
En concordancia con lo dispuesto en líneas anteriores, y de conformidad con Herrera, es procedente una teoría normativa que pretenda redimir la virtud política; y desde la citada perspectiva, es importante distinguir el principio judicial de integridad, con el papel del juez cuando resuelve casos difíciles en aras de encontrar la mejor interpretación de la estructura política y de la doctrina jurídica de su comunidad; todo ello a partir de una serie de principios conocidos y aceptados en el contexto social, reflejo de sus derechos y deberes (Hernández, 2018, p. 194).

\section{Referencias}

Abbagnano, N. (1981/1996). Historia de la fllosofía (4 t.). Barcelona, España: Hora.

Adorno, T., y Horkheimer, M. (2007). Dialéctica de la Ilustración. Barcelona, España: Ediciones Akal.

Ángel, D., y Herrera, J. D. (2011). La propuesta hermenéutica como crítica y como criterio del problema del método. Revista de Estudios de Filosofía, (42), 9-29. Recuperado de file:///C:/Users/Usuario/Downloads/11565-35692-1-PB.pdf

Bernstein, R. (1985). Beyond objetivism and relativism: science, hemeneutics, and praxis. Philadelfia, PA: University of Pennsylvania Press.

Blanco, C. (2011). La integración andina en el marco constitucional de los países miembros de la Comunidad Andina (CAN). Revista IUSTA, 1(34), 107-134. Recuperado de http://revistas.usta.edu.co/index.php/iusta/article/view/3109/2976

Bobbio, N. (1982). Hans Kelsen y Max Weber. UNAM. Recuperado de https://archivos. juridicas.unam.mx/www/bjv/libros/2/970/5.pdf

Castro, G. (2018). Una aproximación teórica a la obra de Arturo Valencia Zea. De la posesión y la función social de la propiedad: el gran problema jurídico del siglo XX en Colombia, revisión histórico jurídica. Revista Via Inveniendi et Iudicandi, 13(1), 9-54. DOI: http://dx.doi.org/10.15332/ s1909-0528.2018.0001.01. Recuperado de http:// revistas.usantotomas.edu.co/index.php/viei/article/view/4265/4042

Da Costa, R. (2006). Las definiciones de las siete artes liberales y mecánicas en la obra de Ramón Llull. Anales del Seminario de Historia de la Filosofia, 23, 131-164. Recuperado de http://www.redalyc.org/pdf/3611/361133107008.pdf

Duek, M. C. (2009). Max Weber: posición política, posición teórica y relación con el marxismo en la primera etapa de su producción. Convergencia, 16(50), 249-280. Recuperado de http://www.scielo.org.mx/pdf/conver/v16n50/v16n50a10.pdf 
Gershenson, C. (2000). Historia de la filosofia: empirismo vs. racionalismo. UNAM. Recuperado de http://turing.iimas.unam.mx/ cgg/jlagunez/filosofia/historia-EmpirismoVSRacionalismo.htm

Hernández, O. (2018). La segunda instancia: Una probabilidad de la sentencia en mínima cuantía. Revista Via Inveniendi et Iudicandi, 13(1), 189-215. DOI: http://dx.doi. org/10.15332/s1909-0528.2018.0001.07. Recuperado de http://revistas.usantotomas. edu.co/index.php/viei/article/view/4271/4048

Herrera, J. (2017). La responsabilidad médica frente a la reforma del Código de Procedimiento Civil y del Código Contencioso Administrativo. Revista IUSTA, 1(46), 85-114. DOI: http://dx.doi.org/10.15332/s1900-0448.2017.0046.04. Recuperado de http:// revistas.usta.edu.co/index.php/iusta/article/view/3527/3417

Higuera Jiménez, D. M. (2018). Juicio a la legitimidad del legislador en Colombia. Revista Verba Iuris, 13(40), 25-47. Recuperado de file://C:/Users/Usuario/Downloads/1555Texto\%20de1\%20art\%C3\%ADculo-2373-1-10-20180705.pdf

Ihering, R. (2003). La voluntad en la posesión. Crítica del método jurídico reinante. México D. F., México: Tribunal Superior de Justicia del Distrito Federal.

Kelsen, H. (2000). Teoría pura del derecho. Bogotá D. C., Colombia: Editorial Unión.

Kelsen, H. (2008). Autobiografía. Bogotá D. C., Colombia: Editorial Universidad Externado de Colombia.

Lazarte, R. (2005). Max Weber: ciencia y valores. Bogotá D. C., Colombia: Editorial Homo Sapiens.

Llano, J. (2017). Teoría del derecho, neoconstitucionalismo y derechos diferenciados. Revista Verba Iuris, 12(38), 13-32.

López, P. (2005). Metodología en el pensamiento y obra de Max Weber. Kinesis, (2). Revista electrónica de metodología e historia del derecho. Revista del Instituto de Metodología e Historia de la Ciencia Jurídica. Madrid, España.

Marx, K., y Engels, F. (1848/1998). Manifiesto del partido comunista. Barcelona, España: Crítica.

Nino, C. (1980). Algunos modelos metodológicos de "ciencia" jurídica. Valencia, Venezuela: Editorial Universidad de Carabobo.

Padrón, J. (2007). Tendencias epistemológicas de la investigación científica en el siglo XXI. Cinta de Moebio. Revista de Epistemología de Ciencias Sociales, (28), 1-32.

Russell, B. (1946/1961). A History of Western Philosophy. London, UK: Allen \& Unwin. Torres-Vásquez, A. (2001). Introducción al Derecho. Bogotá D. C., Colombia: Temis.

Torres, Y., y Ramírez, O. (2018). La responsabilidad civil de las entidades de certificación en Colombia. Revista IUSTA, 1(48), 43-71. DOI: https://doi.org/10.15332/ 
s1900-0448.2018.0048.02. Recuperado de http://revistas.usta.edu.co/index.php/iusta/ article/view/4086/3881

Umbarila Rodríguez, J. I. (2018). Naturaleza e ineficacia institucional en la América española. Revista Verba Iuris, 13(40), 149-174.

Villalba, M. (2016). Cábala y aojamiento en el Tratado de la fascinación de Enrique de Villena. Melancolía 1(0), 30-50.

Voltaire. (1985). Elogio histórico de la razón. Barcelona, España: Planeta.

Weingarten, C. (2016). Contradicciones jurisprudenciales. Aplicaciones de las presunciones en el derecho del consumo. El Derecho - diario de doctrina y jurisprudencia. N.o 13.981, año LIV, 1-4. 